\title{
Contraceptive Discontinuation and Unintended Pregnancy: An Imperfect Relationship
}

By Siân Curtis, Emily Evens and William Sambisa

Siân Curtis is research associate professor, Department of Maternal and Child Health, and faculty fellow, Carolina Population Center, University of North Carolina, Chapel Hill, NC, USA. At the time this study was conducted, Emily Evens was a doctoral student in the Department of Maternal and Child Health, and William Sambisa was a postdoctoral fellow at the Carolina Population Center.
CONTEXT: Contraceptive discontinuation is a common event that may be associated with low motivation to avoid pregnancy. If this is the case, a substantial proportion of pregnancies that follow discontinuation will be reported as intended.

METHODS: Demographic and Health Survey data from six countries (Bangladesh, the Dominican Republic, Kazakhstan, Kenya, the Philippines and Zimbabwe) over the period 1999-2003 were used to explore the proportions of pregnancies women reported as intended or unintended following various contraceptive behaviors. Multivariate logistic regression analysis was used to examine the characteristics of women who reported births as intended when they followed contraceptive failure or discontinuation for reasons other than a desire for pregnancy.

RESULTS: The proportion of births reported as intended following contraceptive failure ranged from $16 \%$ in Bangladesh to 54\% in Kazakhstan, and the proportion reported as intended following discontinuation for reasons other than a desire for pregnancy ranged from 37\% in Kenya to $51 \%$ in Kazakhstan. In at least half the countries, associations were found between selected women's characteristics and their reports that births following either contraceptive failure or discontinuation were intended: Factors that were positively associated were women's age and the time elapsed between contraceptive discontinuation and the index conception; factors that were negativelyassociated were increasing number of living children and reporting method failure as opposed to method discontinuation.

CONCLUSION: These findings suggest that underlying variation in the motivation to avoid pregnancy is an important factor in contraceptive discontinuation.

International Perspectives on Sexual and Reproductive Health, 37(2):58-66, doi: 10.1363/3705811
A critical element in preventing unwanted and mistimed births, and in reducing the need for induced abortions, is the proportion of couples adopting a contraceptive method who continue to use it or another method. 1,2 Analyses of survey data have demonstrated that contraceptive discontinuation is common. ${ }^{2-4}$ In a comparative analysis of contraceptive histories collected in Demographic and Health Surveys (DHS) from 15 developing countries, for example, the percentage of users who discontinued using any method within 12 months for quality-related reasons (method failure, side effects, partner disapproval, health concerns and cost) varied from $9 \%$ in Zimbabwe to 34\% in the Dominican Republic. ${ }^{5}$ In each of these countries, discontinuation for quality-related reasons was more common than that for reduced need (desire to get pregnant, marital dissolution, menopause).

\section{BACKGROUND}

The decision to continue or discontinue use of a contraceptive involves a number of factors-the acceptability of contraceptive options, current and future circumstances, and fertility desires. ${ }^{2}$ Despite the expected significance of fertility desires in deciding whether to continue contraceptive use, the majority of cases of contraceptive discon- tinuation are not driven by the desire to get pregnant. According to DHS surveys in the last five years, the proportion of discontinuations that were due to a desire to get pregnant ranged from $12 \%$ in Azerbaijan (2006) to $40 \%$ in Zimbabwe (2005-2006). 2,6

High rates of contraceptive discontinuation for reasons other than the desire for pregnancy are a public health concern because of their association with negative reproductive health outcomes. In countries with moderate to high contraceptive prevalence, the majority of unintended pregnancies are the result of contraceptive discontinuation or failure. , 7,8 Blanc et al. found that in 14 of 15 less developed countries examined, more than half of recent unwanted births were preceded by contraceptive failure or discontinuation. ${ }^{5}$ Discontinuation for reasons other than a desire to get pregnant was also strongly associated with mistimed and unwanted pregnancies in Guatemala. ${ }^{9}$ Additional research has associated discontinuation for reasons other than the desire for pregnancy with unmet need for contraception and induced abortion. ${ }^{7,8}$ Furthermore, unintended pregnancy has been associated with increased risks of maternal morbidity, health behaviors during pregnancy that are associated with adverse maternal health, and adverse fetal, infant and child health outcomes. ${ }^{10-12}$ Unintended 
pregnancy has also been associated with negative psychological effects among mothers and their children. ${ }^{13}$

Demographic characteristics such as fertility intention, age, parity and marital status have been most consistently related to continuity of contraceptive use. , $^{3,14}$ Socioeconomic factors, such as women's education and socioeconomic status, tend to be less strongly associated with discontinuation. ${ }^{3,14,15}$ Knowledge of the factors that may lead to contraceptive discontinuation remains incomplete, and a better understanding is hampered by the lack of a comprehensive framework that acknowledges the multiple and complex reasons that influence the decision to switch methods or stop using one altogether. While many studies have concluded that considerable unexplained variation in the duration of contraceptive use remains after controlling for factors about which information is available, underlying variation in the motivation to avoid pregnancy is likely a significant factor in discontinuation. ${ }^{3,15,16}$

Some studies in the United States have shown that women do not necessarily report pregnancies as unintended following contraceptive failure or discontinuation (for reasons other than a desire to get pregnant). For example, Trussell et al. found that only $68 \%$ of pregnancies resulting from contraceptive failure were reported as unintended. ${ }^{17}$ They also found that only $59 \%$ of women who reported an unintended pregnancy following contraceptive failure said they felt unhappy or very unhappy about the pregnancy. ${ }^{17}$ Furthermore, inconsistent or no contraceptive use has been found to be more common among women who reported that they would be happy about an unintended pregnancy than among those who said they would be neutral or unhappy about it. ${ }^{18}$

Less research has been conducted on the dimensions of pregnancy intentions in developing countries. In a study of women's ambivalence about pregnancy intentions in Burkina Faso, Ghana and Kenya using DHS data from 2003, about one-quarter of women in the first two countries who reported wanting to delay or stop childbearing said it would be no problem or a small problem if they got pregnant in the next few weeks (defined as ambivalent intentions); this proportion was much higher in Kenya $(43 \%) .{ }^{19}$

Hence, many women are ambivalent about avoiding pregnancy, and many express both positive and negative feelings. ${ }^{20}$ This led Bachrach and Newcomer to argue that pregnancy intentions fall along a continuum with multiple dimensions. ${ }^{21}$ The work of Schoen et al., who found that the probability of having a subsequent birth declined monotonically as women's reported intention for another birth was measured along the continuum "yes, very sure" to "yes, unsure" to "no, unsure" to "no, very sure," supports this theory. ${ }^{22}$ More recently, Santelli and colleagues demonstrated that more nuanced indicators of pregnancy intention that capture different dimensions and strengths of intentions were strongly associated with U.S. women's decision to have an abortion rather than a live birth. ${ }^{23}$ These studies provide further evidence that fertility inten- tions fall along a continuum and that the intensity of those intentions is an important factor in subsequent fertility behavior, and by implication, in subsequent contraceptive adoption and discontinuation. Given this continuum of fertility intentions, contraceptive continuation is likely to be an indicator of a strong motivation to avoid getting pregnant, while method discontinuation may reflect weak motivation.

No studies in developing countries have examined the proportion of pregnancies women report as unintended following contraceptive failure. However, Barden-O'Fallon et al. found that $7 \%$ of live births in Guatemala that were reported as intended followed recent contraceptive discontinuation for reasons other than a desire to get pregnant. ${ }^{9}$ Furthermore, little research has been conducted in developing countries on the influence of motivation to avoid pregnancy on contraceptive discontinuation, other than indirectly through a desire to space or limit future pregnancies.

Using DHS data from six countries, the present study explores the proportion of pregnancies reported as unintended when they follow contraceptive discontinuation, and attempts to identify the characteristics of women who report pregnancies as intended when they follow contraceptive failure or discontinuation for reasons other than to get pregnant. We hypothesize that many discontinuations are associated with low motivation to avoid pregnancy; this would be reflected in a significant proportion of pregnancies following discontinuation being reported as intended. Furthermore, we predict that the proportion of pregnancies occurring after discontinuation that are reported as intended will be most strongly linked to variables that are associated with motivation, such as stage of family formation (e.g., age, number of living children or whether a woman has reached her ideal family size) and contraceptive behavior (e.g., the reason for discontinuation, the method used, or the time elapsed between discontinuation and the birth).

\section{METHODS \\ Data}

This study uses data from six nationally representative DHS household surveys. These surveys employed two-stage sampling to collect information on a wide range of health and reproductive behavior indicators, and offer advantages for comparative analysis because they use standardized instruments and standardized training, data collection and data processing procedures. We selected surveys from Bangladesh, the Dominican Republic, Kazakhstan, Kenya, the Philippines and Zimbabwe to achieve wide geographic coverage and variation in family planning environments. The survey year ranges from 1999 to 2003, * and the sample size from 4,800 to 23,384 women.

\footnotetext{
*Since this analysis was conducted, more recent surveys in the DHS program have become available in all the countries studied except Kazakhstan. Including these surveys would have widened the period considered to 1999-2007. However, because the relevance of these findings is not dependent on the currency of the data, we limited our analysis to surveys conducted in the period 1999-2003.
} 
TABLE 1. Selected fertility and family planning indicators in study countries, Demographic and Health Surveys, 1999-2003

\begin{tabular}{lllll}
$\begin{array}{l}\text { Country and } \\
\text { year of survey }\end{array}$ & $\begin{array}{l}\text { Total fertility } \\
\text { rate for } \\
\text { women } \\
\text { aged 15-49 }\end{array}$ & $\begin{array}{l}\text { \% of married } \\
\text { women aged } \\
\text { 15-49 using } \\
\text { any method }\end{array}$ & $\begin{array}{l}\text { \% of women who } \\
\text { discontinued } \\
\text { method in } \\
\text { first year* }\end{array}$ & $\begin{array}{l}\text { \% of births } \\
\text { that were } \\
\text { unintended }\end{array}$ \\
\hline Bangladesh (1999-2000) & 3.3 & 54.3 & 48.3 & 32.8 \\
Dom.Rep.(2002) & 3.0 & 69.8 & 47.5 & 43.2 \\
Kazakhstan (1999) & 2.0 & 66.1 & 38.5 & 17.2 \\
Kenya (2003) & 4.9 & 39.3 & 37.6 & 44.5 \\
Philippines (2003) & 3.5 & 48.9 & 39.1 & 44.3 \\
Zimbabwe (1999) & 4.0 & 53.5 & 20.2 & 37.4
\end{tabular}

*Proportion of contraceptive users who discontinued any reversible method because of method failure, desire to get pregnant, health reasons or other reasons in the first 12 months of use. Switching from one method to another was considered a discontinuation of the original method. IIn the five years preceding the survey.

TABLE 2. Percentage distribution of live births by mother's preceding contraceptive behavior, according to country

\begin{tabular}{lrrrrrr} 
Country & $N$ & \multicolumn{2}{l}{ Discontinuation } & Nonuse & Total \\
\cline { 3 - 5 } & & \multicolumn{2}{l}{$\begin{array}{l}\text { Method } \\
\text { failed }\end{array}$} & $\begin{array}{l}\text { Desired } \\
\text { pregnancy }\end{array}$ & $\begin{array}{l}\text { Other } \\
\text { reason }\end{array}$ & \\
\hline Bangladesh & 6,881 & 7.8 & 16.6 & 11.5 & 64.1 & 100.0 \\
Dom. Rep. & 10,733 & 11.1 & 16.0 & 18.9 & 54.0 & 100.0 \\
Kazakhstan & 1,420 & 8.0 & 16.4 & 6.9 & 68.7 & 100.0 \\
Kenya & 6,001 & 6.8 & 9.3 & 8.5 & 75.4 & 100.0 \\
Philippines & 6,898 & 11.4 & 7.0 & 8.8 & 72.9 & 100.0 \\
Zimbabwe & 3,504 & 8.2 & 23.6 & 11.9 & 56.3 & 100.0
\end{tabular}

With the exception of Bangladesh, ${ }^{*}$ the surveys collected information on pregnancies, births and contraceptive use from both married and unmarried women aged 15-49. Contraceptive histories were collected for the five years prior to the survey using a calendar that recorded monthly contraceptive use, pregnancy and birth status, and the reason for discontinuing use. ${ }^{24}$ These data allowed the timing of contraceptive behavior prior to each live birth to be determined. ${ }^{\dagger}$

\section{Variables and Analysis}

Using data from the contraceptive calendar, we categorized the most recent contraceptive use behavior in the pregnancy interval before each live birth as follows: contraceptive failure, discontinuation of contraceptive use to get pregnant, discontinuation for other reasons ${ }^{\ddagger}$ or no use. Our rationale for this categorization was that women who discontinued for reasons other than a desire to get preg-

*Because of cultural sensitivities regarding interviewing never-married women about sexual behavior and contraceptive use, the Bangladesh DHS interviewed only ever-married women. The calendar used in this survey covered contraceptive use prior to marriage for women who married during the period.

tMethodological studies have shown that contraceptive use histories collected using the calendar format are more complete, internally consistent and accurate than data collected using a traditional approach with structured questions (Goldman N, Moreno L and Westoff C, Peru Experimental Study: An Evaluation of Fertility and Child Health Information, Columbia,MD, USA:Institute for Resource Development/Macro Systems; and Princeton NJ, USA: Office of Population Research, Princeton University, 1989; and Westoff C, Goldman N and Moreno L, Dominican Republic Experimental Study: An Evaluation of Fertility and Child Health Information, Columbia, MD, USA: Institute for Resource Development/Macro Systems; and Princeton NJ, USA: Office of Population Research, Princeton University, 1990). Curtis and Blanc found evidence that heaping of reported durations of use on preferred digits was not severe enough to significantly affect estimates of nant actively discontinued (unlike women who became pregnant while using a method), but did not express a desire to get pregnant (unlike women who discontinued use to get pregnant). For a woman's first birth, the contraceptive behavior between marriage and the first pregnancy was identified. Each live birth was treated as a separate observation, and thus the analysis is birth-based rather than woman-based; individual women could contribute more than one live birth to the sample.

The surveys also provided information on pregnancy intentions for all live births and current pregnancies in the five years preceding each survey. Pregnancy intentions were defined as whether the child was wanted at the time of pregnancy (wanted then), wanted later or not wanted at any time. Births reported as wanted later or not at all were classified as unintended births; those reported as wanted at the time of the pregnancy were classified as intended. Information on intentions was extracted from the maternity history and matched with the calendar data on contraceptive behavior preceding each live birth.

Descriptive, bivariate and multivariate analyses were performed. Cross-tabulations were used to examine the bivariate relationship between preceding contraceptive behavior and reported intention by country. Next, we conducted a multivariate logistic regression analysis to identify associations between selected explanatory variables and the probability of reporting a birth following discontinuation or failure as intended. Only births following contraceptive failure or discontinuation for reasons other than to get pregnant were included in the multivariate analysis, since this is the subset of births that we would expect to be unintended.

Covariates for the multivariate analysis were selected to identify key characteristics that were expected to be associated with motivation to avoid pregnancy. Variables were selected on the basis of a theoretical association with contraceptive discontinuation or because previous analyses had shown them to be associated with discontinuation behavior. $3,14,25$ Social and demographic variables included age $(\leq 24,25-34$ or 35-49), marital status (never-married or married; excluded for Bangladesh) and number of living children (0-2, 3-4 or $\geq 5$; all three variables defined at the time of the index conception), urban or rural resi-

discontinuation. ${ }^{3}$ They also demonstrated that estimates of contraceptive prevalence from the calendar data and current status data at corresponding points in time were similar. Using data for overlapping time periods from the 1992 Morocco DHS and 1995 Morocco Panel Survey, Strickler et al.found that reporting of contraceptive behavior at the aggregate level was fairly reliable; however, individual-level responses, particularly for complex histories, were not reliable (Strickler J et al., The reliability of reporting of contraceptive behavior in DHS calendar data: evidence from Morocco, Studies in Family Planning, 1997, 28(1):44-53).

‡Other reasons included side effects, health problems, partner disapproval, access or availability, desire for a more effective method, inconvenience, infrequent sex, cost, being separated or widowed, being fatalistic, difficulty getting pregnant, marital dissolution, don't know and other. No distinction was made between reasons that suggested reduced need (e.g., infrequent sex, separation or widowhood) and those that did not (e.g., side effects). This distinction was less important here than it often is, because we focused on women who subsequently became pregnant and were consequently exposed to the risk of pregnancy at some point following discontinuation. 
dence, education (none, primary or at least secondary) and religion (Christian, Muslim or other).* To capture women's stage of family formation, a variable was constructed to identify whether she had exceeded her ideal family size; this was derived from the reported total desired family size and the number of surviving children prior to the index birth. From these two variables, a threefold classification was made: number of living children less than, equal to or greater than the desired number.

The multivariate models also included type of method used prior to the index birth (pill or other method), reason for discontinuation (contraceptive failure or other reasons), and the months elapsed between the preceding discontinuation and the index conception. Women who experienced a contraceptive failure did not actively discontinue, which we hypothesize will be indicative of higher motivation to avoid pregnancy and lower probability of reporting the subsequent birth as intended. A longer period between a discontinuation and subsequent conception is expected to be associated with changes in personal circumstances and motivations to avoid pregnancy. Consequently, the longer the time elapsed between the two events, the less relevant the discontinuation of the previous methods is expected to be to the intention status of the subsequent birth.

All analyses were conducted using Stata, and survey sample weights were applied. Robust standard errors were estimated to take into account the cluster design of the survey and the fact that women could contribute more than one birth to the sample.

\section{RESULTS}

\section{Family Planning Context}

The total fertility rate among women aged 15-49 was lowest in Kazakhstan (two children per woman) and highest in Kenya (five children per woman). All six countries had moderate to high contraceptive use: The use of any method among married women aged 15-49 ranged from $39 \%$ in Kenya to $70 \%$ in the Dominican Republic (Table 1). Method mix (not shown) varied: Oral contraceptives were the most common method in both Bangladesh and Zimbabwe, injectables were the most popular in Kenya, and long-acting and permanent methods were the most common in the Dominican Republic (female sterilization) and Kazakhstan (IUDs); traditional and folk methods were the most popular in the Philippines (the pill was the most common modern method). ${ }^{6}$

Contraceptive discontinuation rates were high in all countries. The percentage of women who discontinued a method in the first year of use for any reason ranged from 20\% in Zimbabwe to 48\% in Bangladesh and the Dominican Republic (Table 1). In every study country but Kazakhstan, the top three reasons for discontinuation

*The most prevalent religion in each country was made the dummy variable; hence, the reference category was affiliation to other religion and no affiliation. The majority religion for Bangladesh and Kazakhstan was Islam, whereas for the other countries it was Christianity.
FIGURE 1. Percentage distribution of unintended births, by mother's preceding contraceptive behavior, according to country

$\%$

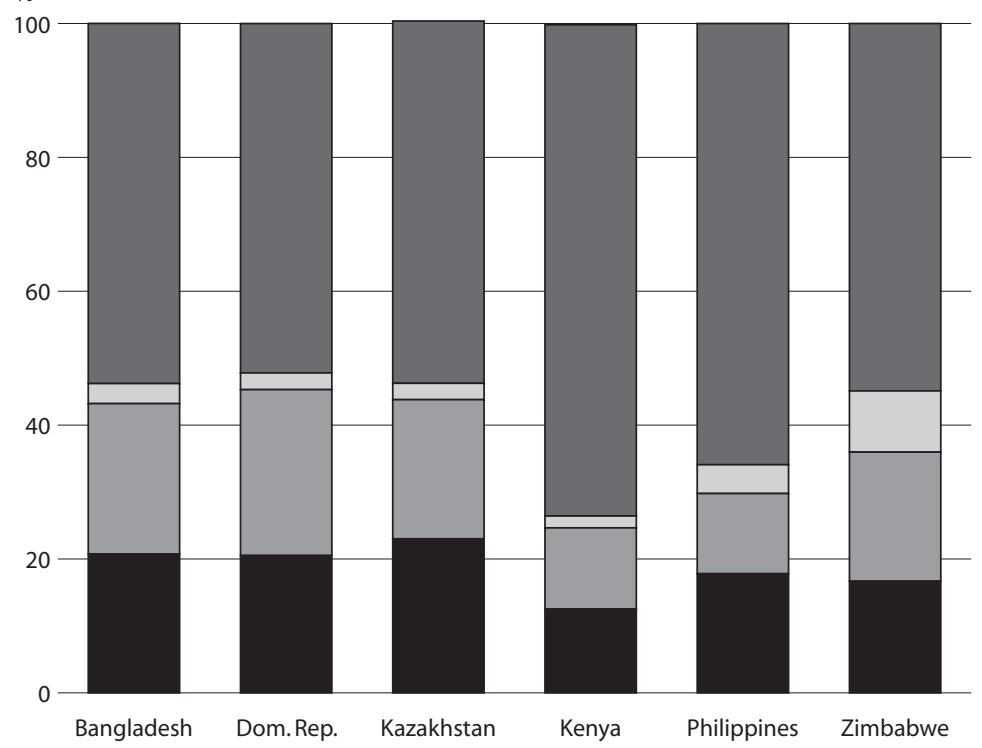

Nonuse

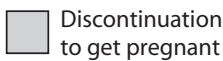

Discontinuation
for other reason Contraceptive failure

were the desire to get pregnant, contraceptive failure and side effects, though the order varied across countries (not shown). In Kazakhstan, the most common reasons for discontinuation were contraceptive failure, desire for a more effective method and health concerns; the desire to get pregnant was the fourth most frequently cited reason. $6,26,27$

FIGURE 2. Percentage distribution of intended births, by mother's preceding contraceptive behavior, according to country

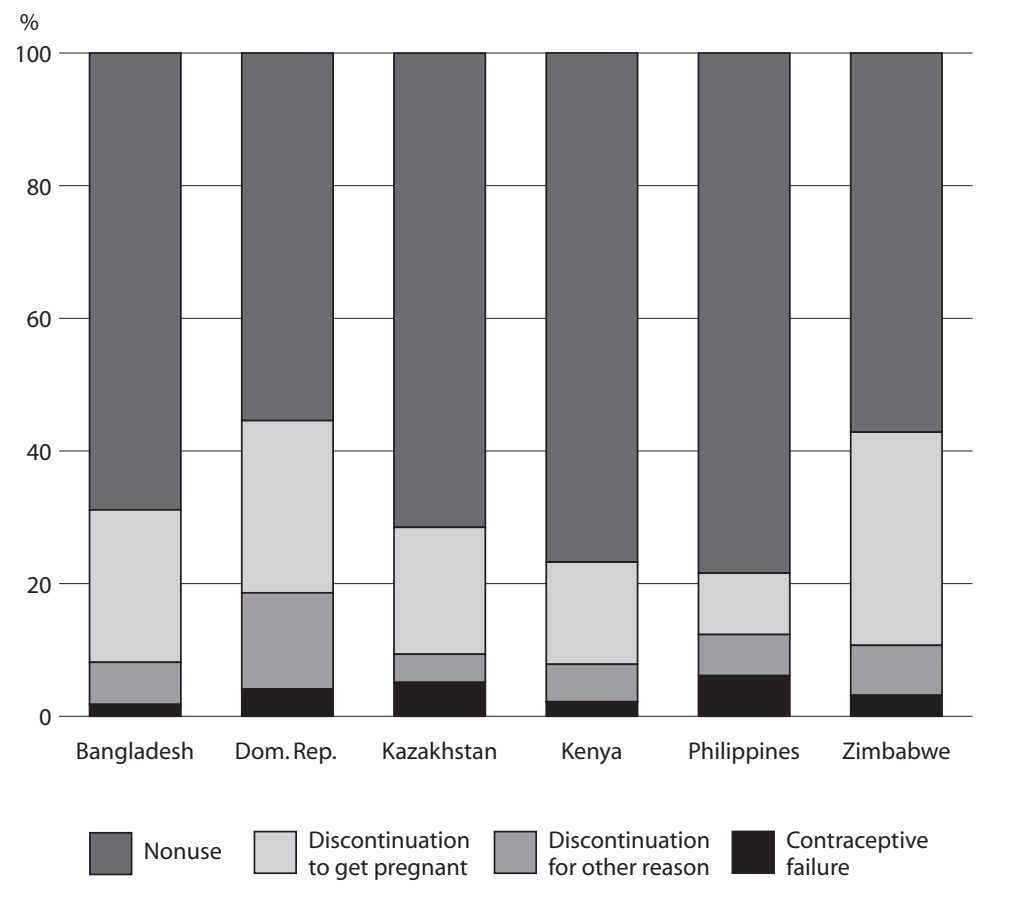


TABLE 3. Percentage distribution of live births by intendedness, according to country and mother's preceding contraceptive behavior

\begin{tabular}{|c|c|c|c|c|c|}
\hline \multirow{2}{*}{$\begin{array}{l}\text { Contraceptive behavior } \\
\text { and country }\end{array}$} & \multirow[t]{2}{*}{$\mathrm{N}$} & \multirow[t]{2}{*}{ Intended } & \multicolumn{2}{|c|}{ Unintended } & \multirow[t]{2}{*}{ Total } \\
\hline & & & $\begin{array}{l}\text { Wanted } \\
\text { later }\end{array}$ & $\begin{array}{l}\text { Not } \\
\text { wanted }\end{array}$ & \\
\hline \multicolumn{6}{|l|}{ Contraceptive failure } \\
\hline Bangladesh & 538 & 15.6 & 45.0 & 39.4 & 100.0 \\
\hline Dom.Rep. & 1,186 & 21.2 & 57.1 & 21.7 & 100.0 \\
\hline Kazakhstan & 113 & 53.5 & 26.8 & 19.7 & 100.0 \\
\hline Kenya & 409 & 17.7 & 43.4 & 38.9 & 100.0 \\
\hline Philippines & 781 & 29.5 & 36.5 & 34.0 & 100.0 \\
\hline Zimbabwe & 287 & 24.2 & 63.6 & 12.2 & 100.0 \\
\hline \multicolumn{6}{|c|}{ Discontinuation to get pregnant } \\
\hline Bangladesh & 1,141 & 94.2 & 4.0 & 1.8 & 100.0 \\
\hline Dom.Rep. & 1,699 & 93.3 & 5.1 & 1.6 & 100.0 \\
\hline Kazakhstan & 232 & 97.6 & 0.8 & 1.6 & 100.0 \\
\hline Kenya & 560 & 91.6 & 4.9 & 3.5 & 100.0 \\
\hline Philippines & 481 & 72.4 & 16.2 & 11.5 & 100.0 \\
\hline Zimbabwe & 824 & 85.5 & 11.1 & 3.4 & 100.0 \\
\hline \multicolumn{6}{|c|}{ Discontinuation for other reasons } \\
\hline Bangladesh & 789 & 37.7 & 30.2 & 32.1 & 100.0 \\
\hline Dom.Rep. & 2,013 & 43.9 & 37.9 & 18.2 & 100.0 \\
\hline Kazakhstan & 98 & 51.4 & 15.9 & 32.6 & 100.0 \\
\hline Kenya & 510 & 36.8 & 31.9 & 31.3 & 100.0 \\
\hline Philippines & 604 & 38.6 & 29.1 & 32.3 & 100.0 \\
\hline Zimbabwe & 416 & 39.7 & 46.4 & 13.9 & 100.0 \\
\hline \multicolumn{6}{|l|}{ Nonuse } \\
\hline Bangladesh & 4,400 & 73.2 & 17.0 & 9.8 & 100.0 \\
\hline Dom.Rep. & 5,760 & 58.7 & 28.3 & 13.0 & 100.0 \\
\hline Kazakhstan & 971 & 87.2 & 6.3 & 6.4 & 100.0 \\
\hline Kenya & 4,502 & 56.7 & 24.5 & 18.8 & 100.0 \\
\hline Philippines & 4,991 & 59.1 & 22.3 & 18.6 & 100.0 \\
\hline Zimbabwe & 1,969 & 63.7 & 31.0 & 5.3 & 100.0 \\
\hline
\end{tabular}

The proportion of births in the five years prior to the DHS survey that were unintended ranged from $17 \%$ in Kazakhstan* to 45\% in Kenya (Table 1). Kazakhstan was the only country in which fewer than one-third of births were reported as unintended.

\section{Descriptive Analysis}

In all countries, the most common contraceptive behavior preceding a live birth was nonuse, with proportions ranging from $54 \%$ to $75 \%$ (Table 2, page 60 ). Except in the Philippines and the Dominican Republic, discontinuation to get pregnant was the next most common; it was lowest in the Philippines (7\%) and highest in Zimbabwe (24\%). The proportion of live births that occurred following method discontinuation for reasons other than a desire to get pregnant ranged from $7 \%$ in Kazakhstan to $19 \%$ in the Dominican Republic. Overall, the proportion of births preceded by contraceptive failure was relatively low, ranging from $7 \%$ in Kenya to $11 \%$ in the Dominican Republic and the Philippines.

As expected, in all six countries, larger proportions of unintended births than intended births were preceded by contraceptive failure or discontinuation for reasons other than a desire to get pregnant (Figures 1 and 2, page 61). The proportion of unintended births that followed a contraceptive

*A high abortion rate contributes to the relatively low prevalence of unintended births in Kazakhstan. failure ranged from 13\% in Kenya to 23\% in Kazakhstan, while the proportion that followed discontinuation for reasons other than getting pregnant ranged from $12 \%$ in Kenya and the Philippines to $25 \%$ in the Dominican Republic. In each country, at least half of all births reported as unintended occurred following a period of no method use. Except in Zimbabwe, fewer than 5\% of unintended births occurred after discontinuation due to a desire to get pregnant.

The majority of intended births were preceded by either no method use or discontinuation to get pregnant. The proportion of intended births that followed discontinuation for other reasons ranged from $4 \%$ in Kazakhstan to $14 \%$ in the Dominican Republic, while the proportion that followed contraceptive failure ranged from $2 \%$ in Bangladesh to $6 \%$ in the Philippines.

\section{Bivariate Analysis}

The distribution of births by reported intention varied according to contraceptive behavior (Table 3). In all countries except Kazakhstan, large proportions of births following either contraceptive failure or discontinuation for reasons other than a desire to get pregnant were reported as unintended (71-84\% and 56-63\%, respectively). Nonetheless, the proportion of live births reported as intended following contraceptive failure ranged from $16 \%$ in Bangladesh to 54\% in Kazakhstan, while the proportion of such births following discontinuation for reasons other than a desire for pregnancy ranged from $37 \%$ in Kenya to $51 \%$ in Kazakhstan. Among the study countries, Kazakhstan also had the highest proportions of intended births following nonuse ( $87 \%$ ) and discontinuation because of a desire to get pregnant (98\%).

As expected, births following discontinuation due to a desire to get pregnant were the most likely to be reported as intended in all countries (72-98\%); those following contraceptive failure were the least likely to be reported as intended, except in Kazakhstan. Births following nonuse were more likely to be intended (57-87\%) than births following discontinuation for reasons other than a desire to get pregnant $(37-51 \%)$.

\section{Multivariate Analysis}

To explore factors associated with ambivalence about avoiding pregnancy, the multivariate analysis focused on births following contraceptive failure or discontinuation for reasons other than a desire to get pregnant. Only women's age, number of living children, reason for discontinuation, and number of months between discontinuation and the index birth were significant in at least half of the countries (Table 4).

Women aged 35-49 were more likely than those younger than 25 to report a birth as intended following discontinuation or contraceptive failure in the Dominican Republic, Kenya and Zimbabwe (odds ratios, 1.7-2.6). In Bangladesh, the Dominican Republic and Kenya, the odds of reporting a birth as intended were significantly lower among women with at least five children than among 
those with 3-4 (0.2-0.3); those odds were significantly higher among women with 0-2 children in Bangladesh and Kenya (2.1-2.3). In all countries except Kazakhstan, women who gave birth after method failure were less likely to report the birth as intended than were those who gave birth after discontinuing method use for reasons other than to get pregnant (0.3-0.7). Finally, in Bangladesh, the Dominican Republic and Kenya, periods of $7-12$ or 13 or more months between contraceptive discontinuation and pregnancy were associated with increased odds of reporting the baby's birth as intended (1.8-3.3). In Zimbabwe, however, a duration of 7-12 months between these events was associated with reduced odds of reporting the birth as intended (0.4).

\section{DISCUSSION}

The study results support our two hypotheses linking discontinuation to low motivation to avoid pregnancy. We found that relatively high proportions of births were reported as intended following contraceptive failure or discontinuation for reasons other than wanting to get pregnant. Although few consistent relationships were found between socioeconomic factors and such reports, stronger and more consistent associations were found with variables expected to be linked to the desire to get pregnant, such as number of living children, reason for discontinuation, and time elapsed between discontinuation and pregnancy. These findings suggest that underlying variation in the motivation to avoid pregnancy is an important factor in contraceptive discontinuation. Strickler et al. found that reported reason for method discontinuation was the least reliable variable collected in a calendar-based study in Morocco. ${ }^{28}$ Inconsistent reporting could result if multiple factors are involved in the decision to discontinue use; which one is reported on a given day may vary. A desire to get pregnant, or at least a lack of strong desire to avoid pregnancy, could be an underlying factor in method discontinuation, even if it is not reported as the primary reason for stopping use.

Although we found that high proportions of births following contraceptive failure or discontinuation for reasons other than a desire to get pregnant were reported as intended, our findings also demonstrate an expected and consistent relationship: Births following discontinuation to get pregnant were the least likely to be reported as unintended, and births following contraceptive failure were generally the most likely to be considered unintended. These findings are consistent with those of BardenO'Fallon et al. for Guatemala, ${ }^{9}$ and overall they support the idea of a continuum of motivation to avoid pregnancy underlying contraceptive discontinuation behavior.

Although some studies have found evidence that improving the quality of family planning services may reduce the rate of contraceptive discontinuation, ${ }^{29-32}$ other research has found that discontinuation may not be amenable to existing interventions. ${ }^{33-36}$ Our findings highlight the strong role of individual fertility desires in influencing the
TABLE 4. Odds ratios from multivariate logistic regression analysis to identify associations between women's characteristics and their reporting that births were intended following contraceptive failure or discontinuation for reasons other than a desire for pregnancy, according to country

\begin{tabular}{|c|c|c|c|c|c|c|}
\hline Characteristic & $\begin{array}{l}\text { Bangladesh } \\
(\mathrm{N}=1,282)\end{array}$ & $\begin{array}{l}\text { Dom.Rep. } \\
(\mathrm{N}=3,243)\end{array}$ & $\begin{array}{l}\text { Kazakhstan } \\
(\mathrm{N}=202)\end{array}$ & $\begin{array}{l}\text { Kenya } \\
(\mathrm{N}=805)\end{array}$ & $\begin{array}{l}\text { Philippines } \\
(\mathrm{N}=1,373)\end{array}$ & $\begin{array}{l}\text { Zimbabwe } \\
(\mathrm{N}=716)\end{array}$ \\
\hline \multicolumn{7}{|l|}{ Age } \\
\hline$<25$ (ref) & 1.00 & 1.00 & 1.00 & 1.00 & 1.00 & 1.00 \\
\hline $25-34$ & $1.23+$ & $1.23+$ & 0.84 & $1.96^{* *}$ & 1.21 & $1.64 \dagger$ \\
\hline $35-49$ & 0.95 & $1.65^{*}$ & 0.80 & $2.18^{*}$ & 1.02 & $2.59^{*}$ \\
\hline \multicolumn{7}{|l|}{ Education } \\
\hline None (ref) & 1.00 & 1.00 & 1.00 & 1.00 & 1.00 & 1.00 \\
\hline Primary & $0.71 *$ & 0.69 & na & 0.54 & 0.80 & $1.82 \dagger$ \\
\hline zsecondary & $0.66^{*}$ & $0.63+$ & na & 0.44 & 0.61 & $1.91 \dagger$ \\
\hline \multicolumn{7}{|l|}{ Residence } \\
\hline Urban (ref) & 1.00 & 1.00 & 1.00 & 1.00 & 1.00 & 1.00 \\
\hline Rural & 1.10 & 0.86 & 1.10 & $1.58^{*}$ & 0.84 & 1.12 \\
\hline \multicolumn{7}{|l|}{ Religion } \\
\hline Other/none (ref) & 1.00 & 1.00 & 1.00 & 1.00 & 1.00 & 1.00 \\
\hline Christian & na & 1.01 & na & $0.71+$ & 1.00 & 0.97 \\
\hline Muslim & 0.93 & na & 1.14 & na & na & na \\
\hline \multicolumn{7}{|l|}{ Marital status } \\
\hline Never-married (ref) & ) na & 1.00 & 1.00 & 1.00 & 1.00 & 1.00 \\
\hline Married & na & 1.42 & 0.42 & $2.16^{*}$ & 0.92 & $1.90^{*}$ \\
\hline \multicolumn{7}{|c|}{ No. of living children } \\
\hline $0-2$ & $2.09^{*}$ & 1.23 & 1.52 & $2.28^{* *}$ & $1.45+$ & 0.96 \\
\hline $3-4$ (ref) & 1.00 & 1.00 & 1.00 & 1.00 & 1.00 & 1.00 \\
\hline$\geq 5$ & $0.18^{* *}$ & $0.26^{* *}$ & 0.40 & $0.24^{* *}$ & 0.71 & 0.60 \\
\hline \multicolumn{7}{|c|}{ Achieved family size } \\
\hline \multicolumn{7}{|c|}{ Less than desired } \\
\hline (ref) & 1.00 & 1.00 & 1.00 & 1.00 & 1.00 & 1.00 \\
\hline Same as desired & $0.67+$ & $0.60^{* *}$ & 0.47 & $0.64 \dagger$ & 0.93 & $0.58+$ \\
\hline Exceeds desired & 0.85 & $0.45^{* *}$ & 0.41 & 0.99 & 0.83 & $0.21^{* *}$ \\
\hline \multicolumn{7}{|l|}{ Method } \\
\hline Pill & 0.93 & 1.17 & 1.51 & 0.73 & $0.75+$ & $1.60 *$ \\
\hline Other (ref) & 1.00 & 1.00 & 1.00 & 1.00 & 1.00 & 1.00 \\
\hline \multicolumn{7}{|c|}{ Reason for discontinuation } \\
\hline \multicolumn{7}{|c|}{ Contraceptive } \\
\hline failure & $0.48^{* *}$ & $0.41^{* *}$ & 1.59 & $0.53^{* *}$ & $0.73^{*}$ & $0.34^{* *}$ \\
\hline \multicolumn{7}{|c|}{ Other than to get } \\
\hline pregnant (ref) & 1.00 & 1.00 & 1.00 & 1.00 & 1.00 & 1.00 \\
\hline \multicolumn{7}{|c|}{ Mos. between discontinuation and pregnancy } \\
\hline $1-3$ (ref) & 1.00 & 1.00 & 1.00 & 1.00 & 1.00 & 1.00 \\
\hline $4-6$ & $1.43+$ & 1.23 & 2.08 & 1.14 & 0.71 & 0.88 \\
\hline $7-12$ & $1.85^{* *}$ & $1.81^{* *}$ & 1.96 & $2.52^{* *}$ & $1.65 t$ & $0.37^{*}$ \\
\hline$\geq 13$ & $2.94^{* *}$ & $2.09^{* *}$ & 2.27 & $3.30^{* *}$ & $1.53 \dagger$ & 0.82 \\
\hline
\end{tabular}

dynamics of contraceptive use, even among women who express a desire to space or limit their childbearing and initiate use. A better understanding of the strength of women's and couples' motivation to avoid a pregnancy would help them to define and initiate appropriate reproductive health strategies. Studies of contraceptive discontinuation have consistently found lower levels of discontinuation among users of long-acting methods that require active discontinuation (e.g., IUDs and implants) than among users of other reversible methods that require active use (e.g., pills and condoms). ${ }^{2-4,25}$ The ease of maintaining contraceptive use is a critical factor in method choice and needs to be considered in the context of how strongly women and couples want to avoid a pregnancy. 


\section{Limitations}

This study has a number of limitations. It relies on women's retrospective reports of whether their pregnancies were intended or not, and these are known to be subject to recall bias and postevent rationalization, although the extent of these problems is generally not considered sufficient to invalidate the use of such reports. ${ }^{12,37}$ More nuanced measures of pregnancy intention that capture multiple dimensions and intensity, such as those explored by Santelli and colleagues, ${ }^{23}$ would allow a more thorough analysis of the role of ambivalent fertility desires in contraceptive behavior. Calendar data are also subject to recall bias, particularly for the reasons for discontinuation noted above. ${ }^{28}$ Nevertheless, this study points to strong, internally consistent relationships between contraceptive behavior and unintended pregnancy at the population level.

The DHS collects data on the intention status of live births, and does not distinguish between induced and spontaneous abortions except in countries where abortion is legal and widely used. Therefore, our study focuses only on the intention status of live births. Women who are most motivated to avoid a pregnancy following discontinuation will be more likely than other women to terminate pregnancies that occur. ${ }^{23}$ This selection bias probably leads to underestimates of the extent of unintended pregnancy following contraceptive failure or discontinuation for reasons other than a desire to get pregnant. However, our objective was not to examine the full continuum of motivation to avoid pregnancy, but rather to explore the role of motivation in discontinuation by looking at how women report the intention status of live births following failure or discontinuation. The fact that a substantial number of women go on to have births that they report as intended following failure or discontinuation for reasons other than to get pregnant supports our hypothesis that a significant proportion of contraceptive discontinuation is associated with ambivalent fertility desires.

Evidence of the potential selection bias caused by focusing on live births is seen in the results for Kazakhstan, where abortion is legal and widely used; the relatively low levels of unintended births reported following failure or discontinuation for reasons other than a desire for pregnancy were likely due to the widespread use of induced abortion among women who were the most strongly motivated to avoid pregnancy. In general, the extent of this selection effect will depend on the level of use of induced abortion in the population, which in turn will depend on the legal status and social acceptability of abortion in that population.

\section{Conclusions}

Contraceptive discontinuation is a complex process in which the strength of fertility desires plays an important role. Women and couples must weigh their feelings about their chosen contraceptive method with their feelings about pregnancy. While contraceptive discontinuation is clearly a critical factor in unintended pregnancy, not all dis- continuation results in this outcome, and reducing the level of discontinuation will be challenging in light of the ambivalence about both contraceptive options and pregnancy intentions. Ultimately, levels of unintended pregnancy will be reduced by successfully identifying women who strongly want to avoid a pregnancy and finding ways to help them successfully initiate and maintain appropriate contraceptive use.

\section{REFERENCES}

1. Cleland J and Ali M, Reproductive consequences of contraceptive failure in 19 developing countries, Obstetrics \& Gynecology, 2004, 104(2):314-320.

2. Blanc A, Curtis S and Croft T, Monitoring contraceptive continuation: links to fertility outcomes and quality of care, Studies in Family Planning, 2002, 33(2):127-140.

3. Curtis SL and Blanc AK, Determinants of contraceptive failure, switching, and discontinuation: an analysis of DHS contraceptive histories, DHS Analytical Reports, Calverton, MD, USA: Macro International, 1997, No. 6

4. Ali M and Cleland J, Contraceptive discontinuation in six developing countries: a cause-specific analysis, International Family Planning Perspectives, 1995, 21(3):92-97.

5. Blanc A, Curtis S and Croft T, Does Contraceptive Discontinuation Matter? Quality of Care and Fertility Consequences, Chapel Hill, NC USA: MEASURE Evaluation, Carolina Population Center, University of North Carolina at Chapel Hill, 1999.

6. MEASURE DHS, STATcompiler, <http://www.statcompiler.com>, accessed Apr. 22, 2011.

7. Casterline J, El-Zanaty F and El-Zeini L, Unmet need and unintended fertility: longitudinal evidence from Upper Egypt, International Family Planning Perspectives, 2003, 29(4):158-166.

8. Jain A, Should eliminating unmet need for contraception continue to be a program priority? International Family Planning Perspectives, 1999, 25(Suppl.):S39-S43 \& S49.

9. Barden-O'Fallon J, Speizer I and White J, Association between contraceptive discontinuation and pregnancy intentions in Guatemala, Revista Panamericana de Salud Pública, 2008, 23(6):410-417.

10. Centers for Disease Control and Prevention (CDC), Unintended pregnancy prevention, 2011, <http://www.cdc.gov/reproductivehealth/UnintendedPregnancy/index.htm>, accessed Apr. 22, 2011.

11. CDC, Pregnancy risk assessment monitoring system (PRAMS): PRAMS and unintended pregnancy, 2011, <http://www.cdc.gov/ PRAMS/UP.htm>, accessed Apr. 22, 2011.

12. Santelli J et al., The measurement and meaning of unintended pregnancy, Perspectives on Sexual and Reproductive Health, 2003, 35(2): 94-101.

13. Hardee K et al., Unintended pregnancy and women's psychological well-being in Indonesia, Journal of Biosocial Science, 2004, 36(5): 617-626.

14. Ali M and Cleland J, Determinants of contraceptive discontinuation in six developing countries, Journal of Biosocial Science, 1999, 31(3):343-360

15. Zhang F, Tsui AO and Suchindran CM, The Determinants of Contraceptive Discontinuation in Northern India: A Multilevel Analysis of Calendar Data, Chapel Hill, NC, USA: MEASURE Evaluation, Carolina Population Center, University of North Carolina at Chapel Hill, 1999.

16. Steele F, Diamond I and Wang D, The determinants of the duration of contraceptive use in China: a multilevel multinomial discretehazards modeling approach, Demography, 1996, 33(1):12-23.

17. Trussell J, Vaughan B and Stanford J, Are all contraceptive failures unintended pregnancies? Evidence from the 1995 National Survey of Family Growth, Family Planning Perspectives, 1999, 31(5):246-247 \& 260 
18. Sable M and Libbus M, Pregnancy intention and pregnancy happiness: are they different? Maternal and Child Health Journal, 2000, 4(3):191-196.

19. Speizer I, Using strength of fertility motivations to identify program strategies, International Family Planning Perspectives, 2006, 32(4):185191.

20. Zabin L, Ambivalent feelings about parenthood may lead to inconsistent contraceptive use-and pregnancy, Family Planning Perspectives, 1999, 31(5):250-251.

21. Bachrach $\mathrm{C}$ and Newcomer S, Intended pregnancies and unintended pregnancies: distinct categories or opposite ends of a continuum? Family Planning Perspectives, 1999, 31(5):251-252.

22. Schoen R et al., Do fertility intentions affect fertility behavior? Journal of Marriage and Family, 1999, 61(3):790-799.

23. Santelli J et al., Towards a multidimensional measure of pregnancy intentions: evidence from the United States, Studies in Family Planning, 2009, 40(2):87-100.

24. MEASURE DHS, DHS Model Questionnaire with Commentary-Phase 4 (1997-2003), Calverton, MD, USA: ORC Macro, 2001.

25. Steele F and Curtis S, Appropriate methods for analyzing the effect of method choice on contraceptive discontinuation, Demography, 2003, 40(1):1-22

26. Central Bureau of Statistics (CBS), Ministry of Health (MOH) and ORC Macro, Kenya Demographic and Health Survey, 2003, Calverton, MD, USA: CBS, MOH and ORC Macro, 2004.

27. Kazakhstan Academy of Preventive Medicine and Macro International, Kazakhstan Demographic and Health Survey, 1999, Calverton, MD, USA: Academy of Preventive Medicine and Macro International, 1999.

28. Strickler J et al., The reliability of reporting of contraceptive behavior in DHS calendar data: evidence from Morocco, Studies in Family Planning, 1997, 28(1):44-53.

29. Koenig M, Hossain M and Whittaker M, The influence of quality of care upon contraceptive use in rural Bangladesh, Studies in Family Planning, 1997, 28(4):278-289.

30. Pariani S, Heer D and Van Arsdol Jr., MD, Does choice make a difference to contraceptive use? Evidence from East Java, Studies in Family Planning, 1991, 22(6):384-390.

31. RamaRao S et al., The link between quality of care and contraceptive use, International Family Planning Perspectives, 2003, 29(2):76-83.

32. Cotton N et al., Early discontinuation of contraceptive use in Niger and the Gambia, International Family Planning Perspectives, 1992 18(4):145-149.

33. Frontiers in Reproductive Health, Philippines and Senegal quality of care: services improve quality of care but fail to increase FP continuation, Washington, DC: Population Council, 2002, OR Summary 30.

34. Aradhya K, Improving contraceptive continuation: focus on hormonal methods-a review of the literature, background paper for interagency workshop on Improving Contraceptive Continuation: Partnering to Generate and Apply Knowledge for Better Results, Nov. 29-30, 2005, Washington, DC: Family Health International, 2005.

35. Leon F, Rios Z and Zumaran A, Final Report: Improving ProviderClient Interactions at Peru MOH Clinics-Extent, Benefit, Cost, Washington, DC: Frontiers in Reproductive Health, Population Council, 2002.

36. Costello M, Sanogo D and Townsend J, Final Report: Documenting Impact of Quality of Care on Women's Reproductive Health-Philippines and Senegal, Washington, DC: Frontiers in Reproductive Health, Population Council, 2002

37. Bankole A and Westoff C, The consistency and validity of reproductive attitudes: evidence from Morocco, Journal of Biosocial Science, 1998, 30(4):439-455.

\section{RESUMEN}

Contexto: La discontinuación del uso de anticonceptivos es un evento común que puede estar asociado a una baja motivación para evitar el embarazo. De manera así, una proporción sustancial de los embarazos que se deriven de la disconti- nuación del método, se designará como embarazos planeados. Métodos: Se usaron datos de las Encuestas Demográficas y de Salud de seis países (Bangladesh, Kazajistán, Kenia, las Filipinas, República Dominicana y Zimbabue) realizadas en el período 1999-2003 para explorar el grado en el que las mujeres designaron embarazos como planeados o no planeados según diferentes conductas anticonceptivas. Se utilizó análisis de regresión logística multivariada para examinar las características de las mujeres que designaron sus embarazos como planeados cuando fueron consecuencia de la falla del anticonceptivo o de discontinuación del método por razones distintas al deseo de embarazarse.

Resultados: Después de la falla del anticonceptivo, la proporción de embarazos resultantes que fueron reportados de planeados varió del 16\% en Bangladesh al 54\% en Kazajistán; $y$ después de la discontinuación por razones distintas al deseo de embarazarse, la proporción señalada como planeado varió del $37 \%$ en Kenia al 51\% en Kazajistán. En al menos tres países, se encontraron asociaciones significativas entre las características de las mujeres y sus respuestas en el sentido de que los embarazos derivados de la falla o discontinuación del anticonceptivo fueron planeados: los factores que se asociaron positivamente fueron la edad de las mujeres y el tiempo transcurrido entre la discontinuación y la concepción; los factores que se asociaron negativamente fueron un número creciente de hijos vivos e indicar que hubo una falla del método en lugar de discontinuación del uso del método.

Conclusíon: Estos hallazgos sugieren que la variación que hay detrás de la motivación para evitar el embarazo es un factor importante en la discontinuación del anticonceptivo.

\section{RÉSUMÉ}

Contexte: L'arrêt de la contraception est un événement courant, peut-être associé à une faible motivation de prévention de la grossesse. Si tel est le cas, de larges proportions des grossesses survenant après l'interruption de la contraception sont déclarées comme planifiées.

Méthodes: Les données d'Enquête démographique et de santé de six pays (Bangladesh, Kazakhstan, Kenya, Philippines, République dominicaine et Zimbabwe) pour la période 1999-2003 ont servi à analyser dans quelle mesure les fermmes déclarent leurs grossesses comme planifiées ou non à la suite de différents comportements contraceptifs. Les caractéristiques des femmes ayant déclaré une naissance planifiée après échec contraceptif ou arrêt de méthode pour des raisons autres que le désir d'une grossesse ont été examinées par analyse de régression logistique multivariée.

Résultats: La proportion de naissances déclarées comme planifiées après échec contraceptif varie entre 16\% au Bangladesh et $54 \%$ au Kazakhstan; après arrêt de méthode pour raisons autres que le désir d'une grossesse, la proportion varie entre $37 \%$ au Kenya et $51 \%$ au Kazakhstan. Dans la moitié au moins des pays, plusieurs associations sont relevées entre les caractéristiques des femmes et leur déclaration de naissance planifiée après échec contraceptif ou arrêt de méthode: les facteurs présentant une association positive sont l'âge de la femme et le temps écoulé entre l'arrêt de la contraception et la concep- 
tion indice; ceux présentant une association négative sont le nombre croissant d'enfants en vie et la déclaration d'un échec de méthode par opposition à son arrêt.

Conclusion: Ces observations laissent entendre que la variation profonde de la motivation de prévention de la grossesse est un facteur important d'arrêt de la contraception.

\section{Acknowledgments}

The authors thank Paul Brodish for his Stata programming assistance. Support was provided by the U.S. Agency for International Development (USAID) through the MEASURE Evaluation Project (GPO-A-00-03-00003-00). The views expressed here do not necessarily reflect those of USAID or the U.S. government.

Author contact:sian_curtis@unc.edu

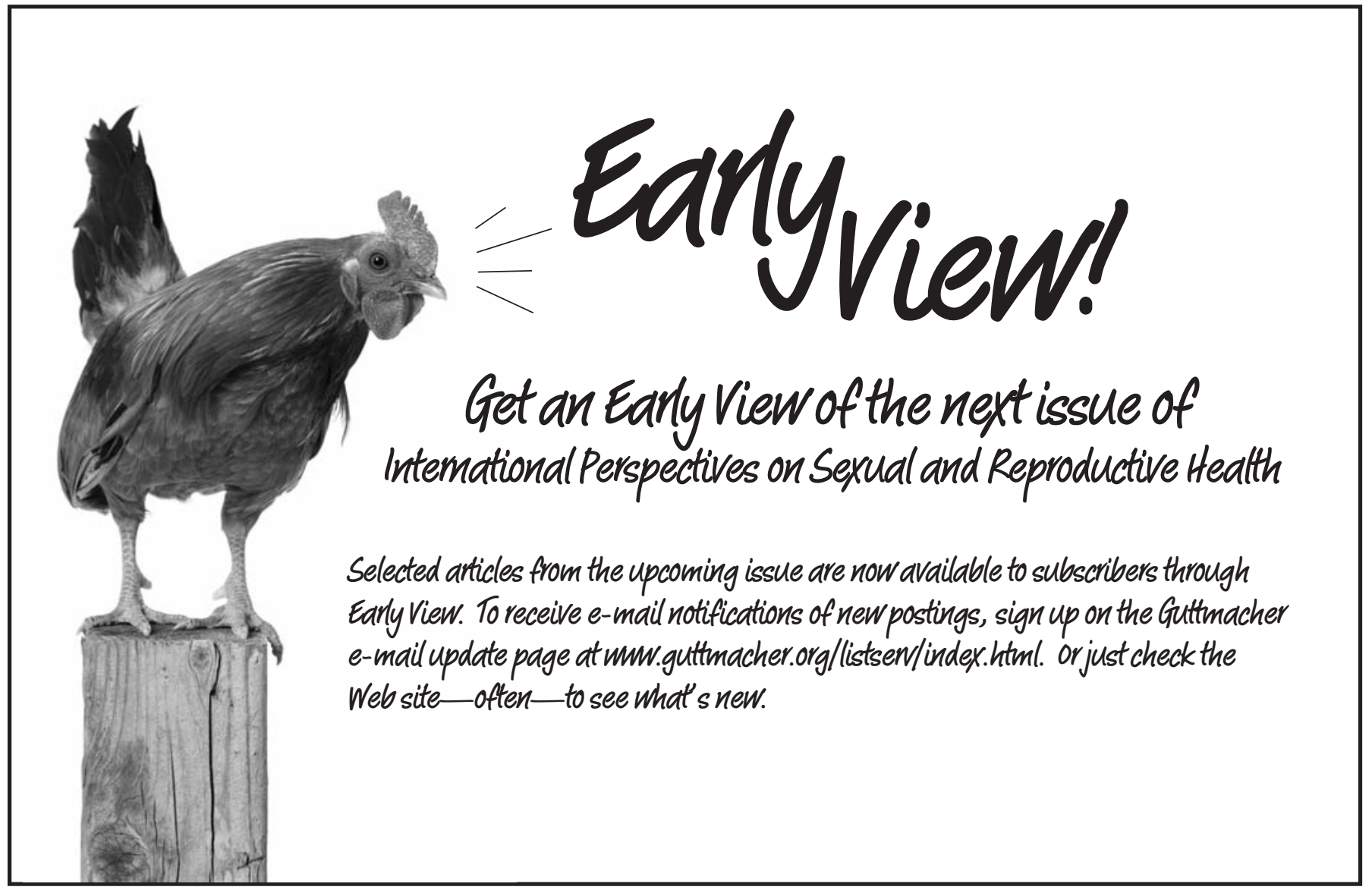

